\title{
Relendo a Política de Contracepção: O Olhar de um Profissional Sobre o Cotidiano das Unidades Públicas de Saúde
}

\author{
Rereading Contraceptive Policy: Health Professionals' Views of Daily \\ Routine in Public Health Services
}

\section{Auta Iselina Stephan-Souza ${ }^{1}$}

STEPHAN-SOUZA, A. I. Rereading Contraceptive Policy: Health Professionals' Views of Daily Routine in Public Health Services. Cad. Saúde Públ., Rio de Janeiro, II (3): 408-424, Jul/Sep, 1995.

This essay is part a larger study on the relationship between the Brazilian government and contraceptive policy and precedes a survey performed in health services in Rio de Janeiro. It is also intended to analyze what health care professionals and users think about contraception. It presents considerations by a social worker with experience in family planning activities in outlying public health care services and also provides data facilitating activities in this area. It thus touches on some elements that interfere in practical work in this field, such as academic life and social representation, in addition to submitting a written critique to PAISM (the Brazilian Ministry of Health's Program for Integrated Women's Health Care) as an official contraceptive policy.

Key words: Contraception; Contraceptive Policy; Family Planning; Women's Health

INTRODUÇÃO

Este ensaio pretende oferecer uma contribuição aos profissionais das unidades de saúde que trabalham com a contracepção. Tem início em 78, em um monólogo permanente sobre os rumos da política contraceptiva a se estende até a presente década, com acréscimo de contribuições de outros profissionais, suas dúvidas e críticas assemelhadas. A nossa pretensão é aqui iniciar a discussão dos elementos: formação acadêmica, significados da contracepção, política contraceptiva e representações sociais que estão presentes nas ações de contracepção de modo a facilitar o estabelecimento da interface com os profissionais que desenvolvem trabalho nesta área.

Ele é também parte de um estudo mais amplo que visa abordar a relação do Estado neoliberal com a política contraceptiva assim como anali-

Praia João Caetano, 145, apto. 903, Niterói, RJ, 24210-400, Brasil. sar a situação da pobreza e controle demográfico, e precede a uma investigação nas unidades de saúde do Rio de Janeiro que objetiva retratar o pensamento de profissionais e usuárias de saúde sobre a contracepção. Por isso as afirmativas neste momento têm origem nas interrogações próprias de um profissional que viveu a experiência da prática contraceptiva e que pretende checá-la junto a outros profissionais com idêntica prática profissional.

A par da existência de demarcação entre posições controlistas ou natalistas que acompanham as discussões sobre o controle da natalidade, relacionadas com a política tanto em nível internacional a nacional, que de uma forma sutil ou explícita defende a postura controlista, pretendemos no presente momento evitar a marcada polarização entre elas. Postergamos esta discussão considerando, entretanto, a importância atual da análise política do Planejamento Familiar/Controle da Natalidade, ao contrário de alguns posicionamentos que possam considerá-la démodé ou ultrapassada. 
Diante de algumas indagações pensamos que o démodé referente ao Planejamento Familiar talvez signifique o sucumbir à força da penetração das entidades controlistas em nosso país nos últimos 30 anos, ou talvez uma maior vinculação a elas, ou ainda, a tendência em subestimar qualquer forma de resistência quanto ao controle da natalidade por parte de profissionais. Isto se dá talvez porque se considera que as entidades controlistas aqui ramificadas cumpriram a meta de contribuir para a redução numérica da população, sem entretanto conseguir que o Estado oferecesse alternativas mínimas de redução da pobreza. Há uma tendência em considerar que o desenvolvimento poderá ser alcançado pelo ângulo da exclusão numérica dos pobres, o que sem dúvida é tendencioso e equivocado.

$\mathrm{O}$ assunto Planejamento Familiar recentemente se constituiu como pauta da Conferência do Cairo (1994), assim como foi em Bucarest em 74 a no México em 84. Dessa forma, reafirma-se a sua contemporaneidade a desconsiderase qualquer abordagem que veja este assunto como superado. Ao contrário, consideramos a pertinência de sua discussão no Brasil, dentro das diferentes conjunturas onde se firmaram as posições quanto ao controle da natalidade. Há também interesse especial de análise do quadro neoliberal atual, face às relações da política contraceptiva, tanto interna quanto frente a organismos internacionais.

A conjuntura pós 90 mostrou um período de perda significativa de autonomia na política externa brasileira e segundo Gonçalves (1994: 128)

"a subordinação aos interesses a estratégias dos EUA é tão evidente que difcilmente encontram-se na história contemporânea do Brasil registros de uma política externa tão subordinada quanto neste início de década. Neste sentido, exemplos são facilmente encontrados na discussão sobre a posição do Brasil nos foros internacionais, reforma da legislação brasileira de propriedade industrial, de controle do capital estrangeiro, liberalização comercial a de negociação da dívida externa"

É fato conhecido a pressão sofrida pelo Brasil durante a Conferência Mundial sobre o Meio
Ambiente ocorrida em 92, não só pelos EUA mas também por seus parceiros do chamado Primeiro Mundo, quanto à necessidade de garantir a política de controle demográfico, sempre fazendo alusão à provável escassez dos recursos naturais. Citamos como exemplo a matéria do jornal O Globo (1992), onde o representante do governo inglês propõe "uma última tentativa para que a Rio-92 não se tome um desastre retórico, tomando o caso dos menores abandonados no mundo inteiro para destacar que nenhum país pode cuidar do meio ambiente se a sua população cresce mais rapidamente que sua economia" (grifo nosso). A subordinação da política externa brasileira aos países hegemônicos em relação ao controle da natalidade é histórica a durante as últimas décadas por aquela foi guiada, mesmo quando os nossos governantes reafirmavam no discurso a nossa soberania, sem entretanto conseguir garanti-la na prática, o que demonstra a brusca queda da natalidade nos últimos anos.

Na plenária do $9^{\circ}$ Encontro de Assuntos Populacionais realizado em 1994 em Caxambu, estudiosos como Berquó, Sawyer a Patarra que estiveram presentes na Conferência do Cairo, ao explicitarem que "ainda que não existam metas explícitas, a preocupação com o excessivo crescimento populacional está presente" e "que o documento do Cairo tem um ranço controlista sim" ou ainda que "o documento é controlista porque assume como objetivo em seu plano, que em 20 anos se atinge o desenvolvimento econômico e desenvolvimento sustentado", não deixam dúvidas quanto à intenção do I Mundo em definir um quantitativo populacional adequado a um padrão determinado de crescimento, sem contudo precisar sua responsabilidade efetiva para conseguir a reversão deste quadro, que necessita muito mais de soluções políticas do que simplesmente de ampliação na distribuição de insumos contraceptivos. Como em 20 anos será atingido o desenvolvimento econômico a sustentado?

Segundo Marques (1991: 17) o "conceito de desenvolvimento sustentado proposto tem três vertentes principais: crescimento econômico, eqüidade social a equilíbrio ecológico. Apregoa o 'espírito de responsabilidade comum', como processo de mudança no qual a 
exploração de recursos materiais, as inversões financeiras e as rotas de desenvolvimento tecnológico deverão adquirir, mundialmente, um sentido harmonioso na construção de um futuro justo, seguro a próximo...". Diante desta, fica muito difícil falar em eqüidade social para o conjunto da população mundial, quando acordos firmados submetem parcela considerável da população dos países do Terceiro Mundo ao controle da natalidade, usando para isto tecnologias que lesam o organismo, principalmente daquela população vista como “desnecessária”. Vinte anos é tempo demais para se esperar a reversão do quadro de miséria, mas ao mesmo tempo é curto para se atingir o desenvolvimento, mesmo que seja parcial. Supomos que esta pretensão passa somente pela contenção numérica da população pobre, a pouco ou nada pela distribuição eqüitativa dos recursos econômicos do mundo. Em termos de Primeiro Mundo nada foi feito em relação à limitação de consumo.

Ainda de acordo com o mesmo grupo de estudiosos presentes à Conferência do Cairo foi substituído o conceito amplo de Saúde Reprodutiva para Direitos Reprodutivos por considerar a necessidade de evoluir para a área do Direito: "toda pessoa tem o direito de desfrutar do padrão de saúde física a mental, saúde reprodutiva a planejamento familiar sem coerção ou coação”. A evolução de Saúde Reprodutiva para Direito Reprodutivo sem coerção ou coação significa adequado acesso aos serviços de saúde ou é apenas uma troca semântica que usa de novo simbolismo para manter o atual quadro de desigualdades, onde a reprodução populacional é tratada diferencialmente?

Nesta ocasião, surgiu um questionamento sobre as circunstâncias a as condições necessárias para uma possível subordinação entre as ações de desenvolvimento a as questões demográficas.Embora nas discussões com a plenária tenha se afirmado que o documento do Cairo não continha metas demográficas, houve uma reação crítica por parte da mesma, reafirmando a existência de tais medidas, já que o documento estabelecera que " $64 \%$ dos $17 \mathrm{mi}$ lhões de dólares seriam aplicados em Planejamento Familiar, bem acima dos atuais $5 \mathrm{mi}$ - lhões". Parece-nos bastante plausível pensar que, para uma determinada estimativa de recursos existe uma correspondência relativa à população que quer se reduzir, a fim de que sejam cumpridas as metas de controle demográfico.

$\mathrm{Na}$ Conferência em Bucarest, em 74, de imediato o governo brasileiro se colocou em defesa de nossa soberania quanto aos rumos demográficos, sem contudo, internamente conseguir frear a forte penetração das entidades controlistas internacionais, assumindo a partir daquele momento a posição dualista. De acordo com a afirmação de Rocha (1993: 33)

"nos anos 70, considera-se, que o governo brasileiro apresentava um comportamento ambíguo, durante quase todo o período: de um lado, com uma posição cautelosa em direção a uma política social que envolvesse a fecundidade, de outro, com uma posição permissiva face às entidades particulares que atuavam no setor. Julga-se que aquela moderação estava relacionada às objeções a uma política controlista, colocadas não somente par parte de vários segmentos do Estado como também da própria sociedade. De fato, apesar da perspectiva neomalthusiana haver tido uma relativa aceitação em certos momentos, nunca se aproximara do consenso”.

Em 94, esta questão continua vaga a imprecisa. No plano da política interna o planejamento familiar/controle da natalidade é por um lado parcialmente desenvolvido em programa que depende de iniciativas individuais de alguns governos municipais, e por outro se dilui na discussão da descriminalização do aborto e regulamentação da laqueadura tubária, sem maiores perspectivas de evoluir a incorporar a concepção do Direito à Saúde Reprodutiva. Daí podermos supor que a imprecisão convém à política contraceptiva que permanentemente se pautou na hesitação, evitando desta forma confrontos, ora em nível interno ora externo, facilitando o vazio desejado para o fortalecimento da política antinatalista.

Seguramente a multiplicação de recursos proposta pela Conferência do Cairo traz conseqü- 
ências para a política contraceptiva brasileira. Perguntamos, entretanto, se ela se coaduna com os encaminhamentos dados no Congresso Nacional, por um número expressivo de parlamentares, a quais as influências recebidas de posições do movimento feminista organizado. Indagamos também em que medida o aumento dos recursos financeiros para o Terceiro Mundo, afeta o Brasil e, por último, qual seria a possibilidade real do PAISM (Programa de Atenção Integral à Saúde da Mulher) em priorizar as ações qualitativas. Por alteração qualitativa entende-se a definição política a metodológica abrangente que dê curso a uma prática pedagógica para atingir o contingente significativo da população feminina presente ou ainda distante do universo dos serviços de saúde. Para este patamar ser atingido é necessário uma definição política do governo para determinar a quem de fato se destina o programa contraceptivo, já que é notória a insuficiência de recursos para atender a todo o conjunto da população feminina. Ou seja, o PAISM não cumpre de fato a proposta de cobertura ampla a toda a população feminina, conforme está contido no seu texto básico. A qual parcela populacional ele realmente se destina?

Por isto é contraproducente discutir a política contraceptiva desvinculada da concepção de pobreza, já que é ela a maior receptora dos meios contraceptivos; apesar de seu texto original propor a universalização da cobertura a toda população feminina, as classes mais favorecidas a melhor aquinhoadas de informações sobre os insumos recorrem basicamente aos serviços privados para suprir suas necessidades contraceptivas, o que acontece também sem a menor avaliação por parte dos órgãos sanitários. Segundo Abranches et al. (1989: 27) "no Brasil, atualmente convivem duas formas de pobreza. Aquela de natureza estrutural, mais arraigada e persistente, associada ao desdobramento histórico de nosso padrão de desenvolvimento, e a pobreza cíclica, que se agravou com a crise de desemprego, a queda da renda, sua concentração crescente e a aceleração inflacionária”.

Se os recursos contraceptivos são insuficientes para cobrir a necessidade de toda a população feminina, estes talvez estejam sendo destinados à população parte da "pobreza cíclica" que tem maior oportunidade de recorrer às unidades de saúde. Pode-se supor que para a "pobreza estrutural", não coberta pelo sistema de saúde, caberiam os programas de esterilização, onde para a maioria das mulheres não é dado conhecer o caráter de irreversibilidade. A esta população, excluída do processo produtivo, são também destinados os novos experimentos que alteram o equilíbrio hormonal do organismo, sem que o governo exerça qualquer tipo de fiscalização sanitária, deixando de avaliar os riscos a que está submetida.

A pobreza estrutural, dentro do nosso entendimento, é o objeto principal do controle da natalidade. Para isto tenta-se o impedimento da reprodução física desta população com remota possibilidade de vir a ser absorvida pelo mercado. Sabemos que a única maneira de conter de fato a pobreza é o desenvolvimento econômico e social que viabiliza o acesso a todas as formas da educação a saúde, capaz de fortalecer o pleno emprego para obter como resultado a melhoria das condições de vida. Porém, de acordo com o modelo econômico adotado, com escassas possibilidades de desenvolvimento, a contracepção não pode continuar sendo implementada sob a infuência apenas das teses feministas de pressão junto ao Estado. Hoje, o PAISM só é viabilizado quando tem em seu interior profissionais que de alguma forma tenham ligação com os movimentos feministas. Isto reduz o seu significado a contribui pouco para a afirmação do direito reprodutivo. De posse desse e de outros direitos sociais que lhe assegurem as condições necessárias à sobrevivência, as mulheres, com certeza, optam por regular sua fertilidade.

Questionamos o mérito da ajuda externa, se é de fato necessária, a não ser para estreitar ainda mais os compromissos de dependência dentro da política neoliberal, ao estabelecer um quantitativo de recursos viável às previsões estabelecidas em acordos de base econômica. Questionamos também a importância do instrumento - Programa de Ação do Cairo - para pressionar o governo brasileiro, visto que esse, diante do interesse conjunto da Nova Ordem Mundial, de transnacionalização da economia, já havia anteriormente se comprometido com a redução populacional. A nosso ver a exigên- 
cia é o rápido desenvolvimento somado à garantia da cidadania plena, dentro dela contido o direito às condições mínimas de vida e a conseqüente regulação da fertilidade. O Programa do Cairo criou o espaço político para serem externadas as formas peculiares de análise do problema populacional; entretanto, a política a ser assumida continua sendo definida dentro do estreito filtro dos ajustes externos entre países pobres e ricos.

Feitas estas considerações preliminares, é preciso, também, situar que a defesa de uma posição natalista é também desmedida: a extensão do território, a ambição internacional pelas riquezas econômicas, as predições de ordem moral/religiosa, não sustentam mais qualquer política de cunho natalista. Para a menor parcela da população a necessidade de controle da prole é fato já determinado pela educação a cultura. expressado também pela viabilidade da mulher frente ao mercado de trabalho e na formação gradativa do processo de formação da cidadania. Não obstante, para a maior parcela da população, fora do acesso à educação, à saúde e à formação da cidadania, urge primeiro a implementação de políticas sociais tipo educação a saúde, que respondam às necessidades básicas. As necessidades contraceptivas e posteriormente a incorporação do direito à saúde reprodutiva são decorrência deste complexo de ações interdependentes.

\section{A FORMAÇAO ACADÊMICA E O CONTROLE DA NATALIDADE}

De posse destas reflexões que foram também sedimentadas no cotidiano do trabalho nas unidades de saúde, percebemos que a prática profissional reflete a dificuldade dos profissionais em lidar com tantos elementos no tocante à contracepção. Dificuldade esta que estaria centrada principalmente na deficiente formação profissional na área de Saúde da Mulher. Para os profissionais da área biológica que recebem apenas a preparação técnica quanto à aplicação dos diversos contraceptivos, ficam lacunas provocadas pelo desconhecimento dos múltiplos determinantes (políticos, sociais, econômicos, ecológicos e também psicológicos) que cercam a contracepção. Embora os profissionais oriundos das áreas sociais sejam despreparados em relação à técnica contraceptiva, quase sempre porém, reúnem sufici- ente sensibilidade, advinda da própria formação, percebendo com maior clareza a interseção das inúmeras variáveis presentes na realização deste trabalho. Porém, a sensibilidade em si é insuficiente para sustar os desacertos encontrados nos trabalhos de contracepção, sendo importante a reflexão sobre a totalidade dos elementos condicionantes desta política.

Se o conhecimento dos profissionais de ambas as áreas apresentam estas lacunas, poderse-ia então presumir que estes profissionais reunidos complementariam cada um o trabalho do outro. Entretanto, isto não acontece e na maioria das vezes são identificadas posições de litígio, atribuídas ora à prepotência, ora à representação social ou, ainda, a fatores de ordem institucional, tais como: estrutura de poder, divisão do trabalho intelectual e manual, distribuição de recursos, que em geral circundam a política contraceptiva dentro das unidades de saúde.

Segundo Schraiber (1989: 56) "ao formar/ qualificar o trabalhador intelectual a escola fornece-the um grau de instrução referente a cada ramo parcelar do saber, apresentando o grau de instrução como garantia de inserção nas delimitações hierárquicas (em níveis 'compativeis') do trabalho intelectual no interior do mercado de trabalho”. Esta delimitação hierárquica do trabalho intelectual se faz sentir na prática contraceptiva, quando por exemplo, parte dos médicos assume para si a responsabilidade de definir qual o contraceptivo que deve ser usado independente de fatores como conhecimento do corpo, sexualidade, ou vontade manifesta. A parcela de saber recebida, para eles, legitima a indicação, mesmo que esta possa contrariar o desejo expresso. Ela também pode agir como coação, levando à imposição de práticas lesivas à saúde, dentre elas a esterilização.

A mesma autora complementa: " a divisão trabalho manual/intelectual se reproduz no interior do próprio trabalho intelectual, e faz da mesma forma que a divisão primeira: pelo parcelamento do saber, a pela valorização/desvalorização de seus ramos parcelares, assim como das tarefas que compõem os diferentes processos do trabalho intelectual" (Schraiber, 1989: 57). Mesmo de forma implícita, são identificadas estas heranças da formação na área biomédi- 
ca tradicional. Esta começa a ser mudada quando é dada ênfase ao conhecimento da saúde pública, que coloca num mesmo patamar os elementos biológicos e os sociais no processo de saúde a doença. A valorização/desvalorização dos ramos de saber é percebida, vindo daí as interpretações múltiplas sobre a contracepção. A divisão do conhecimento, o status diferenciado entre os saberes, a tendência em desqualificar os trabalhos em saúde pública como menos importantes do que as especialidades, são elementos que se interpõem na rotina das unidades de saúde.

O pensamento de Carneiro \& Werneck (1992: 46) diz que

"nos importa questionar ainda sobre a situação dos profissionais de saúde em relação à cultura da sexualidade, conhecimento dos processos e ciclos, ideologia do ensino na área da saúde, subordinação do setor às ideologias intervencionistas, despreparo, situação profissional. Além disso, impotentes diante de uma situação social que explode no setor saúde, acabam por exercer um papel sem a reflexão necessária sobre seus atos. Assim, pobreza, desqualificação profissional, desemprego, insatisfação sexual, desresponsabilização masculina no ato sexual, solidão da mulher no cuidado com os filhos, ignorância acerca do funcionamento dos ciclos da procriação em seu próprio corpo, falta de perspectivas existenciais são fatores que estão presentes na relação entre mulheres que buscam a esterilização e técnicos que lhes atendem ou até lhes apresentam a alternativa”.

Ele leva-nos a tentar compreender o grau de interferência superposta destes díspares problemas. Este emaranhado de situações desenha o quadro real da fragilidade, da fragmentação, da desinformação, onde ações profissionais, conjugadas às semelhantes dificuldades por parte das usuárias, convivem juntas no trabalho contraceptivo.

Os elementos acima evocados talvez possam explicar a relutância dos profissionais em dar início ao trabalho de contracepção e os conflitos que sistematicamente surgem entre os membros da equipe: para uns, o trabalho seria direcionado a uma vinculação explícita aos organismos com capacidade de abastecer as unidades de saúde, desconsiderando a origem a as implicações políticas do uso destes insumo; enquanto que, para outros, seria essencial o pleno conhecimento da política contraceptiva e o controle das etapas da elaboração a comercialização do produto.

A nosso ver, havendo uma adequada formação, os principais elementos da política contraceptiva circunscritos ao significado dado ao planejamento familiar ou controle da natalidade, seriam analisados com o sentido de proporcionar posteriormente uma clara adesão conceitual a política a uma destas concepções ou definir outra, a partir da reflexão a da crítica. A formação também implica o conhecimento científico dos insumos contraceptivos em relação à sua produção, distribuição e consumo.

A formação deficiente talvez seja responsável pela tendência muito encontrada em rotular como pantletários ou ideológicos aqueles trabalhos dos profissionais que se preocupam com a integridade dos elementos que interagem na área contraceptiva. Aqueles que rotulam talvez desconheçam que este assunto polêmico precisa ser decodificado a melhor compreendido, de modo a evitar os constantes agravos à saúde, tais como: mutilações desnecessárias provocadas pela laqueadura tubária, o uso de hormônios de alta dosagem, tais como os injetáveis, desenvolvidos com materiais de origem física e química estranhos ou nocivos ao organismo feminino.

Muitas das usuais práticas contraceptivas, como por exemplo a esterilização, puderam acontecer talvez graças a processo de indução e/ou coação por parte de profissionais afetos ao controle da natalidade, que submeteram a mulher a problemas no campo emocional e físico. Há duas formas de se reduzir a população: uma é eliminar por meios drásticos, como por exemplo a esterilização; a outra é aumentar o padrão de vida. Qual a pretensão política oficial, já que permite a contínua prática da esterilização de forma direta ou por meio das cesáreas desnecessárias?

Compreendendo a rede que envolve os diferentes atores no núcleo do Estado neoliberal brasileiro e percebendo as variações ideológicas dos diferentes discursos referentes à 
contracepção, os profissionais têm dificuldade em assumir a exercer a prática educativa. A posse do conhecimento é primordial fator para levar a usuária a questionar a opção, nem sempre voluntária, pela esterilização, assim como dos outros procedimentos de controle da natalidade que trazem lesões à saúde. Presumimos que, antes de qualquer interesse, o desconhecimento pode aproximar num mesmo plano a idêntica representação social que parcela dos profissionais, assim como das usuárias, fazem sobre a contracepção.

A insuficiente formação profissional, consideramos, imputa à ideologia, como sendo um fator desacelerador do trabalho contraceptivo. Todas as vezes em que a ideologia é identificada, a ela é atribuída qualquer insucesso deste trabalho. No entanto, se conhecida, a ideologia pode ser vista tanto como dominação ou deturpação, ou ainda, código ou grelha que orienta as diferentes ações. A ideologia é um conceito amplo que diz muito, e, às vezes, muito pouco. Contudo, está sempre presente, mesmo quando aparece a afirmação de que "não se tem ideologia".

Para Chauí (1994: 175) "uma maneira de operar da ideologia é a produção do imaginário social, através da imaginação reprodutora. Recolhendo as imagens diretas a imediatas da experiência social (isto é, do modo como vivemos as relações sociais), a ideologia as reproduz, mas transformando-as num conjunto coerente, lógico e sistemático de idéias que funcionam em dois registros: como representações da realidade (sistema explicativo ou teórico) e como normas e regras de conduta e comportamento (sistema prescritivo de normas e valores)".

Enfrentar a relação ideologia/representações sociais a contracepção neste estudo, se ousado, poderá no entanto, contribuir para elucidar alguns elementos que permitam facilitar o trabalho dos profissionais que hoje encaminham a contracepção nas unidades de saúde. Significa tentar entender as posições do senso comum, as distorções na transmissão do conhecimento e dos discursos políticos, o conformismo que considera "tudo natural", as representações sociais manifestas e o significado da omissão e do silêncio.
$\mathrm{Na}$ ausência de formação suficiente, o profissional pode armazenar algumas idéias sobre o controle da natalidade, a partir de suas diferentes inserções sociais, que vão desde a militância política e/ou participação nos movimentos sociais, até as leituras a comunicações que, às vezes feitas sem críticas, são reproduzidas durance o processo de trabalho. Consideramos que seria mais profícuo se as informações básicas se tornassem parte dos currículos das universidades. Conforme acentua Valla \& Stotz (1993: 91)

"na realidade, suas formações universitárias revelam lacunas justamente nas áreas de conhecimento que se relacionam com os problemas agudos da população trabalhadora (problemas de aprendizagem de crianças das classes populares, vigilâncias epidemiológica e sanitária, saneamento, por exemplo). Nesse sentido, a ótica elitista dos currículos universitários faz com que assuntos tratados nas universidades freqüentemente passem a largo das questões de educação e saúde ligadas às necessidades da população”.

Pressupomos que a absorção do conhecimento, apenas relativa, contribui para a permanência de conflitos e bloqueia a base da formação de uma equipe de trabalho. A precária formação na área da contracepção talvez seja a resposta aos limites encontrados na compreensão da totalidade dos fatores presentes no trabalho contraceptivo, desde a política até o uso das técnicas. Parte dos profissionais restringe-se a desempenhar o trabalho, executando rotinas a normas determinadas, podendo desta forma estar sujeita à manipulação política a ideológica das tendências natalistas ou controlistas.

Os profissionais não recebem conhecimento suficiente para discernir a captar as concepções políticas que norteiam cada uma das propostas de trabalho. De acordo com Szmrecsányi (1988: 24) "Nesse tipo de conhecimento repousa a possibilidade de se debater, sem histeria, a validade dos problemas 'crescimento populacional versus desenvolvimento econômico' ou 'crescimento populacional versus futuras condições de vida da humanidade', em quaisquer das versões (éticas, políticas, econômicas, ecológicas) que a polêmica tem assumido. E como 
desdobramento disto, só um conhecimento solidamente fundado pode servir de orientação para escolha democrática acerca da conveniência de políticas natalistas ou antinatalistas". Estes certamente devem ser passados durante a formação acadêmica. Atualmente isto não acontece, o que tem aberto espaço para que a "formação contraceptiva" se reduza ao aprendizado das técnicas e seja dada de fato por instituições privadas, orientadas por projetos controlistas. Isto pode talvez explicar o pensamento controlista dominante.

\section{SIGNIFICADO DA CONTRACEPÇÃO}

Enunciadas algumas das dificuldades entre a formação profissional e o trabalho contraceptivo, passamos a discutir o significado da contracepção e suas derivações. Contracepção é entendida como o momento da não concepção, um corte na possibilidade de ocorrer nascimentos, infecundidade provocada pelo uso de anticoncepcionais a interrupção do ato biológico de gerar seres humanos. É um assunto ético por excelência, por ao mesmo tempo envolver aspectos de foro íntimo, junto a aspectos políticos, econômicos a sociais. É assunto pertinente à autodeterminação tanto de um povo, portanto coletivo, como também afeta a autodeterminação individual. Por congregar múltiplos interesses a confrontos, traz permanentemente uma carga de problemas que indistintamente atingem os dois planos: o coletivo e o individual.

A contracepção vista como infecundidade provocada pelo uso de anticoncepcionais pode ser interpretada dentro de duas óticas: planejamento familiar ou controle da natalidade. É encontrada uma tendência generalizada em não discriminar a conceituação que cada uma destas óticas carrega, sendo por muitos indistintamente usada uma a outra interpretação. Porém, vemos que a convivência superposta destas interpretações contribui para perpetuar a ambigüidade da prática contraceptiva. Acreditamos que o desconhecimento é a causa maior destas interpretações, somado às representações sociais, ideológicas a políticas que cada profissional carrega.

O Planejamento Familiar pode ser entendido como o ato de escolha consciente por um número arbitrado de filhos a este só ocorreria como conseqüência de um processo educativo.
Esta denominação sempre foi a preferida nos discursos oficiais, desde 65 , quando aqui foram implantados os primeiros serviços de contracepção. Na década de 70, ela sustentou slogans políticos do tipo "paternidade responsável" ou "gestação de alto risco", alegando também a necessidade de fazer frente "ao número absurdo de abortos". Tudo isto com o sentido de justificativa ao Planejamento Familiar.

Entretanto, até o início da década de 80, o uso desta denominação nunca se fez acompanhar da prática educativa, que oportunizaria o conhecimento integral dos contraceptivos, condicionada pelo conhecimento tanto do corpo, como da sexualidade feminina. A conotação mais precisa do Planejamento Familiar que comporta a prática educativa só veio a acontecer após 83, quando elegeram o PAISM como política contraceptiva oticial. Todavia, seu lançamento não se fez acompanhar da prática educativa correspondente, sendo ainda extremamente reduzido o número de iniciativas neste sentido, ficando difícil identificar as mais significativas.

O Controle da Natalidade, no entanto, darse-ia por intermédio de medidas impositivas induzidas por pressões do Estado. O Controle da Natalidade foi assumido claramente em estados como a China, a Índia a outros. Entretanto, no Brasil, este controle foi efetivado com a redução do número médio de filhos de 6,5 na década de 40 para 3,5 em 90 (de acordo com o relatório no 2 da CPI/CN de 1993) sem uma clara definição política do Estado, conforme nitidamente aconteceu nos outros países. Por isso, para Pena (1991: 97) o Estado Brasileiro pode ser interpretado como o "Estado de duas caras" quando se "assiste à implementação de uma política populacional que se faz fora dele, ou em suas franjas, por iniciativa de agentes locais associadamente a agências privadas filantrópicas. Esses agentes contam não apenas com a passividade do Estado, mas com recursos financeiros, administrativos a de pessoal dele advindos".

Concordamos com o pensamento de Pena e vemos que no Brasil, a política populacional passou por diferentes estágios, mas sempre perpetuando estas tônicas - permissividade e dualidade. É um Estado permissivo por conviver com duas situações: oficialmente, sempre se 
postou defensivo em relação a sua autonomia e contrário à ingerência externa quanto a sua política populacional. Contudo, internamente permitiu a expansão do trabalho das entidades controlistas, que até mesmo usaram o espaço público de suas unidades de saúde, de certos hospitais a de universidades. Desta forma ocupam o vazio deixado nos currículos e usam como aliado o silêncio, onde nem tudo pode ou deve ser revelado.

A dualidade mais se expressou em 74, quando, na Conferência de Bucarest, o Brasil se posiciona de forma considerada natalista, ao sustentar a não necessidade de controlar a natalidade, ou de mudar os rumos do desenvolvimento por causa das questões demográficas. Na ocasião, considerou também o país subpovoado a não aceitou a intromissão externa nestas questões que diziam respeito a sua soberania. Em contrapartida, a par de toda esta postura, as medidas restritivas de controle da natalidade ocorreram de forma desmedida, assim como foi ampliado o número de organizações internacionais controlistas presentes no país.

Ao longo destes 30 anos a discussão da contracepção no Brasil sempre se fez acompanhar de outra celeuma: o significado do Planejamento Familiar e/ou Controle da Natalidade. Segundo Martine (1993: 12),

"também prejudicada pelo simplismo é a distinção entre Planejamento Familiar (isto é, a capacidade do indivíduo ou do casal de planejar a sua prole) e o controle da natalidade (isto é, um conjunto de ações visando reduzir a fecundidade a assim, o crescimento vegetativo de um grupo ou nação). O primeiro é um direito humano básico a indiscutível. O segundo tem conotações políticas a morais discutiveis em diferentes contextos. Como as pessoas não enxergam a diferença entre os dois, assumem posturas duvidosas: ou militam contra o planejamento familiar porque têm ojeriza a tudo que cheira à interferência na área populacional, ou manipulam os anseios de planejamento familiar para avançar no controle populacional".
Armazenamos dúvidas se esta consideração esgota o conjunto de determinantes que cercam esta polêmica questão e se, da forma como foi por ele colocada, pode contribuir para estreitar a compreensão de seu signifcado.

No Brasil a contracepção sempre foi cercada por ambigüidades: o controle da natalidade conseguiu se efetivar, mesmo na ausência de qualquer política contraceptiva. Esta política que só veio de fato a acontecer em 84 , com a oficialização do PAISM. Enquanto isto, utilizaram-se indistintamente as denominações, planejamento familiar ou controle da natalidade para elementos que se não opostos, pelo menos são diferentes na essência. De acordo com algumas conveniências, essas ambigüidades puderam ainda encobrir ações que comprometiam as alianças com as Igrejas (não só a católica, mas também algumas evangélicas) e com as esquerdas, que continuamente faziam restrições ao Estado quanto à sua ligação com instituições financeiras ou de ajuda humanitária do Primeiro Mundo.

Temos a considerar estas parciais modificações que irão se refletir na década de 80 ; a par das esquerdas terem se colocado a favor das teses natalistas reafirmando a dominação econômica dos países do Primeiro Mundo, em seu interior elas abrigaram esta contradição: os movimentos feministas, por elas referidos na sua quase totalidade, em sua luta por fortalecimento da cidadania e da identidade feminina, reconheceram, no entanto, a necessidade da mulher em estabelecer o limite de sua prole. Passam então as esquerdas a interferir na definição de uma política contraceptiva, agrupando as reivindicações legítimas das mulheres no que concerne ao trabalho a acesso às melhores condições de vida, o que invariavelmente conduzia à reivindicação da limitação da natalidade.

Quanto à Igreja, por força das pressões dos movimentos feministas e de outros movimentos organizados, assim como em função do avanço de outras religiões com posições claras de defesa do controle da natalidade, esta começa a permitir algumas concessões quanto aos chamados "métodos naturais". Na atual década a Igreja chega a aumentar estas concessões, deixando de adotar a posição atual e costumeira frente ao aborto e outras formas de regulação da fertilidade, conforme as apre- 
sentações colocadas pela mídia durante a Conferência do Cairo.

Consideramos que, antes de qualquer interesse humanitário, as instituições controlistas abrigam a determinação de conter a qualquer custo a possibilidade de nascimento da população considerada por elas desnecessária. Ao contrário, pensamos que a eliminação da pobreza é conseqüência muito mais do modelo de desenvolvimento, do que da extinção pura e simples da população pobre. Esta ambigüidade talvez seja proposital ou conveniente e pode ser confirmada no fato de não serem encontradas, nos atuais currículos dos cursos de saúde, ementas que objetivam o estudo da contracepção quanto aos elementos econômicos e políticos.

Esta ausência suprime dos profissionais das áreas biológicas maior refinamento para a compreensão da teia de interseções desta área específica e leva a toda sorte de interpretações, facilitando a deturpação de idéias sobre a contracepção. Podemos inferir que aí reside a matriz das interpretações sujeita às manipulações de cunho ideológico, que podem carregar elementos de dominação, dissimulação ou legitimação decorrentes das diversas concepções sobre a contracepção. Tais elementos fogem a qualquer controle do que está contido na proposta oficial. Desta forma o PAISM é desenvolvido apenas pelos mesmos grupos que o reivindicaram anteriormente, sendo totalmente desconhecido pela maioria dos profissionais de saúde. Ele se reduz a experiências esparsas e localizadas, em caráter de exceção, como nos municípios onde os seus dirigentes haviam anteriormente adotado compromisso com esta proposta.

Os profissionais formados sem o conhecimento do PAISM, especialmente da política contraceptiva nele contida, reproduzem em sua maioria a sistematicamente nos trabalhos o falso ou impreciso conhecimento sobre a contracepção. Continuam a desconhecer na totalidade os efeitos externos a internos da política contraceptiva, além de ignorarem a pertinente composição material dos contraceptivos. Estes fatos podem ser os responsáveis pelo estabelecimento feito por eles de uma mecânica relação entre a pobreza e a necessidade de planejamento familiar. Podem usar esta denominação mais próxima da concepção mais correta, mas tendem na prática a enfatizar a defesa do controle da natalidade. No discurso verbal ocultam a expressão controle da natalidade, face à conotação negativa que esta carrega, e para não contrariar setores da Igreja ou provocar a resistência de grupos profissionais de orientação política de esquerda. Muitos optam pela expressão planejamento familiar ou outra qualquer denominação como justificativa para frear a prática de abortos. Alegam que aceitam o controle da natalidade sob quaisquer formas mesmo as irreversíveis, por considerá-to uma alternativa melhor do que o aborto. Indagamos se esta junção não é feita por mera conveniência, pois o tema aborto chama para si uma ampla repercussão no campo da Moral, do Direito, da preservação da Família e da Religião. Tratá-to de forma interligada à contracepção favorece a aprovação de toda e qualquer política, que será apoiada principalmente em função da conotação dada ao aborto, relegando a segundo plano as importantes questões políticas a econômicas que acompanham a contracepção. Esta é uma das emergentes questões ainda tratadas no campo exclusivo da Moral e da Religião, devendo evoluir para o campo do Direito de formação da cidadania.

\section{ELEMENTOS DE CRÍTICA À POLÍTICA CONTRACEPTIVA}

As dúvidas e certezas do Estado brasileiro frente à política contraceptiva talvez possam ser entendidas através das duas fases que compõem a história da contracepção no Brasil: a primeira quando em meados da década de 60 aqui passaram a atuar as entidades controlistas, no cenário onde começam a ocorrer as ferrenhas disputas entre os antinatalistas a anticontrolistas; a segunda a partir de 74, quando foi viabilizado um novo discurso que culminou na elaboração do PAISM, criado em 84 como um programa de saúde integral à mulher.

Pautado nos documentos elaborados conjuntamente pelo Ministério da Saúde, pela Secretaria Nacional de Programas Especiais em Saúde e pela Divisão de Saúde Materno-Infantil - Dinsami (MS/SNPES/Dinsami, 1989: 132), analisamos o seguinte texto: 
"a signifcativa queda da fecundidade que começa ser constatada, a partir dos anos 70, na ausência de qualquer política ofcial, demonstra a intensidade do interesse das mulheres pelo planejamento da prole. Como reflexo desses fenômenos, uma das principais reivindicações do movimento de mulheres em suas manifestações dos anos 70 diz respeito ao controle do processo produtivo. Mas a contradição, entre essa necessidade das mulheres, historicamente surgida, e as propostas controlistas acaba por trazer também certa perplexidade a esses movimentos. Ao mesmo tempo em que era preciso situar-se corretamente diante das propostas controlistas era necessário incorporar a demanda efetiva das mulheres pelo Planejamento Familiar"

A ausência de política oficial e a permissividade do próprio Estado foram suficientes para que as entidades internacionais a nacionais controlistas aqui pudessem com facilidade fazer o repasse ideológico de seus objetivos a um expressivo número de profissionais de saúde.

A lacuna deixada pela formação inadequada ou insuficiente propiciou a recorrência justamente às entidades controlistas. Um exame mais apurado poderia oferecer resposta ao significado do desejo expresso sobre o controle da prole por parte das mulheres na década de 70 . Se é fato que uma parcela das mulheres começa a reivindicar os direitos reprodutivos a partir do acesso ao processo educativo e da inclusão no mercado de trabalho, é também fato que o desejo manifesto se circunscreve às campanhas de "paternidade responsável" e "gravidez de alto risco" perfeitamente afinadas com a ideologia controlista. A incorporação das mulheres no mercado de trabalho ou o adequado acesso aos meios educacionais é ainda insuficiente para explicar a demanda pelo controle da prole e a urgência em implantar um programa de regulação da fecundidade, bem antes de outros de urgência reconhecida. Outros determinantes compuseram este quadro.

$\mathrm{Na}$ primeira fase, de 65 a 74, FonsecaSobrinho (1993: 80) localizou do mesmo lado alguns atores sociais, como "o governo norteamericano, preocupado com a 'cubanização' do Nordeste brasileiro, e depois, então, com as repercussões sociais e políticas de uma su- posta 'explosão demográfica' que estaria em curso no Terceiro Mundo; militares, que passaram a ver no crescimento populacional uma ameaça à 'segurança nacional'; grandes empresários, que percebiam na taxa de crescimento demográfico um obstáculo ao desenvolvimento nacional; grupos de médicos, interessados em abrir espaço para o Planejamento Familiar no país”. Estes atores sociais em conjunto deram as condições necessárias para ser implantado o programa de controle da natalidade, sem entretanto publicamente assumir este real intento. Assim utilizavam de eufemismo como "paternidade responsável" ou "controle do número de abortos" para de fato fortalecer a tendência estabelecida por eles, para uso de todos e quaisquer meios contraceptivos visando sustar o crescimento populacional brasileiro.

$\mathrm{Na}$ segunda fase, a partir de 74, segundo o mesmo autor, viabiliza-se um novo discurso:

\section{"A Igreja Católica passou a admitir que a 'procriação' poderia não ser a função} precípua da vida sexual e chegou a assumir o papel de defensora a divulgadora dos 'métodos naturais' de anticoncepção... Os militares perderam espaço, sendo sua teoria geopolítica de ocupação dos 'espaços vazios' superada por outra segundo a qual a 'explosão demográfica' $e$ a 'ameaça interna' que ela significava eram muito mais importantes do que a 'ameaça externa'... As mulheres ativamente presentes neste debate a partir de 75 passaram a reivindicar para si o direito de exercer o que foi identificado como 'controle democrático da reprodução'. Estas mudanças, abriram a clareira na qual o governo edificaria a inauguraria, em 1983, o PAISM - Programa de Assistência Integral à Saúde da Mulher"

(Fonseca-Sobrinho, 1993: 135).

Na década de 80, para Rocha (1993: 31),

"a criação do PAISM, neste contexto, representou uma mudança no Ministério não somente na retórica ali utilizada, mas principalmente no que diz respeito ao fato do discurso tomar uma forma concreta de política pública. Através desse Programa 
buscava-se atender à saúde integral à mulher em todas as etapas de sua vida, incluindo o planejamento familiar, este, porém, como atividade complementar e sem objetivo demográfico. Tal plano apresentava, ainda, o formato de ,uma política social com objetivos - programáticos definidos, com espaço institucional delimitado, a com recursos orçados para sua execução. Esta política, na sua concepção e nas suas características, apesar de contemplar a regulação da prole dentre as suas ações, não representa uma política populacional referente à fecundidade. lsto é, não detém intenções explícitas almejando reduzir, aumentar ou mesmo manter as taxas de crescimento demográfico. Representa isto sim, uma política de corte social na área da saúde, que poderá vir a ter conseqüências da dinâmica da população. Trata-se, pois, de uma preocupação do poder público com relação à reprodução humana, dentre outros aspectos referentes à saúde”.

Esta distinção que a autora levanta é sem dúvida importante, porque, dada a maior abrangência do PAISM, a mulher pôde ser assistida como usuária de saúde, em todos os seus ciclos de vida. Todavia, se de fato o programa não detém intenções explícitas desejando a redução, o aumento ou a manutenção das taxas de crescimento demográfico, toma-se necessário revê-lo, já que hoje continuam sendo ratificados os acordos internacionais quanto às projeções de um quantitativo financeiro para execução da política de regulação contraceptiva, conforme foi estimado durante a Conferência do Cairo. Para o estabelecimento de tal estimativa precisou antes haver a projeção numérica da população, para que depois se identificasse a relação entre população e necessidade quantitativa dos insumos. Qual foi a estimativa populacional prevista para o Brasil?

A política contraceptiva só foi oficializada nos últimos dez anos, e de forma parcial: não houve cobertura à demanda potencial, esta também de inteira responsabilidade do PAISM, mas somente à demanda espontânea. Os insumos continuam quantitativamente insuficientes e os profissionais se mantêm despreparados, considerando a precária formação básica na área de Saúde Reprodutiva. Da mesma forma que no passado os profissionais de saúde continuam recebendo os conhecimentos necessários sobre a contracepção de maneira complementar ou apenas por motivação própria, fora do contexto formal de educação.

É ainda comum a recorrência às entidades controlistas, que ministram cursos pagos, para ensino das técnicas essenciais à aplicação dos métodos contraceptivos. Acompanhando as técnicas, juntam-se repasses ideológicos e indução a novas tecnologias, como por exemplo as feitas sobre o Norplant, Diu, Pílula, Laqueadura a outros, conformadas dentro das orientações dadas pelos organismos controlistas internacionais a instituições nacionais de pesquisa. Estas introduziram os contraceptivos injetáveis e neste momento chegam a experimentar novas técnicas contraceptivas como aquelas que suspendem o fluxo menstrual. No texto do MS/SNPES/ Dinsami (1989: 136) sobre o PAISM está contido que "O Estado deve analisar cuidadosamente os protocolos de pesquisa dos métodos anticoncepcionais em experimentação a acompanhar o desenvolvimento destas pesquisas, para evitar a comercialização de produtos que comprometem a saúde dos usuários". Perguntamos: como o Estado tem, de fato, se desincumbido frente a sua própria determinação?

Ao que parece, muitas destas tecnologias foram aplicadas, sem terem antes seus efeitos devidamente controlados, provocando sérios danos à saúde, como é o caso conhecido de aplicação de Dius, posteriormente vistos pelos laboratórios estrangeiros como cancerígenos, e as pílulas de alta dosagem hormonal de primeira geração, retiradas posteriormente de consumo. Indagamos se foram suficientemente avaliados os seus efeitos sobre o organismo feminino e se é possível estabelecer relação entre a grande incidência de histerectomias em mulheres com mais de 40 anos usuárias das primeiras pílulas contraceptivas e dos primeiros Dius. Estas histerectomias foram justificadas como necessárias à prevenção do câncer, quando este pode ter sua origem justamente no uso dos contraceptivos hormonais de alta dosagem ou no uso de material mecânico e estranho ao organismo como o Diu. 
Hoje, continuamos a questionar como o Estado permite que a mídia divulgue os métodos experimentais, como, por exemplo, os injetáveis, os suspensivos da menstruação, sem fazer o devido contraponto ou ao contrário, chegando até mesmo a apontar em sua defesa. Ao mesmo tempo, como deixa de exercer o controle sobre estas pesquisas, quando ele próprio a assumiu, como de sua inteira responsabilidade? Há certezas do ponto de vista científico que os contraceptivos hoje usados não redundarão em posteriores agravos à saúde?, Conforme situa o MS/SNPES/Dinsami (1989: 135), "O Estado deve exercer rigorosa 'vigilância sanitária' sobre os métodos anticoncepcionais em uso, através do sistema nacional de vigilância sanitária, que inclui as ações do Ministério da Saúde a das Secretarias Estaduais de Saú$d e$ ". A própria experiência prática, já na década de 90, em uma unidade de saúde fora da cidade do Rio de Janeiro, mostrou a apresentação de contraceptivos acondicionados em embalagens que não continham sequer a composição química e muito menos o nome do laboratório onde eram produzidos. Onde está a vigilância? Continuamos ou não sob a concepção do Estado dual, que tudo permite e que contradiz seus próprios princípios?

A existência do PAISM como política contraceptiva oficial não conseguiu demover as práticas de controle da natalidade, que existiam antes de 84. Para a população alijada do processo de produção, é assegurado o controle da natalidade. Este significou a utilização de todo e qualquer meio para cercear o aumento da população pobre, mesmo aviltando os direitos sociais fundamentais. Se visto dessa forma o controle da natalidade não é parte da política oficial, entretanto, é como se fosse.

Segundo o mesmo documento do Ministério da Saúde, "é no final da década de 70 e início de 80 que ocorreram no Brasil as experiêneias de uso e principalmente de abuso dos contraceptivos orais, sem a devida assistência médica, necessária em qualquer programa de planejamento familiar. A esterilização feminina também tem sua prevalência bastante aumentada, representando, apesar de uma prátiea ilegal, a única alternativa que as mulheres tinham para a prática da anticoncepção" (MS/ SNPES/Dinsami, 1989: 135). Esta frase vem contïrmar o quadro de carência de medidas contraceptivas antes da implantação do PAISM. Indagamos porém, se depois de implantado ele conseguiu se expandir significativamente ou continua reduzido a experiências restritas àqueles profissionais já convencidos pela divulgação das teses feministas.

Tratamos de considerar até este momento, apenas o trabalho junto à demanda que busca de forma espontânea as unidades de saúde. E a demanda potencial? Não é também responsabilidade do PAISM? Ou é de antemão considerada excluída, por força do modelo econômico adotado? O texto oficial contida no documento do Ministério da saúde (MS/SNPES/Dinsami, 1989: 135) afirma: "a ingerência do Estado deve restringir-se a garantir, a todos os brasileiros, o acesso aos vários métodos recomendados e às informações necessárias para a decisão consciente”.

\section{A CONTRACEPÇAO E AS REPRESENTAÇÕES SOCIAIS}

Duas fases já descritas deram ensejo à disputa ideológica sobre os rumos da contracepção. Como o discurso da formação acadêmica não carrega este conjunto de informações que poderiam passar por um universo de análise e críticas, pensamos que os futuros profissionais e também os profissionais atuais as identificam em diferentes e/ou opostos espaços e chegam às unidades de saúde, reproduzindo-as em posições superficiais e acríticas. Desta forma representam ideologicamente a contracepção, querendo que o trabalho siga um determinado caminho que invariavelmente esbarra com o do opositor. A ideologia opera atrás de toda a qualquer posição, mesmo nas manifestações de silêncio, e como um código interfere em cada encaminhamento dado ao trabalho na área da contracepção.

As considerações antigas e atuais, que incorporam interpretações opostas sobre a contracepção, ativam as permanentes discordâncias, tornando-as o ponto central da dissolução dos trabalho em equipe, restringindo assim a necessária educação contraceptiva. Neste tipo especial de educação estaria presente o conjunto das informações, que viabilizaria à usuária dos serviços de saúde a opção consciente 
por um contraceptivo adequado à sua saúde e sexualidade. Pensamos também que a prática educativa poderá ser a responsável pelo estabelecimento de um limite a todo o processo que possa induzir ao uso tanto de contraceptivos desconhecidos, como também daqueles que trazem à usuária a perda definitiva de sua capacidade reprodutiva.

Nas unidades de saúde é usual identificar algumas representações sociais semelhantes a esta: "essa população não tem onde cair morta e por isso não pode continuar a ter filhos" ou "o pobre não pode ter filhos e por isso uso mesmo qualquer contraceptivo para evitar que a pobreza aumente" ou "todo contraceptivo é bom porque evita a miséria" ou ainda "o aumento da população é o que ocasiona a fome". Apontamos como referência este conceito de "representação social", que segundo Jovchelovitch \& Guareschi (1994) são

"símbolos construídos coletivamente, de forma compartilhada, por uma sociedade.” (p. 65)

"a atividade psíquica, assim, envolve uma mediação entre o sujeito e o objeto-mundo. Este último reaparece sob a forma de representações, recriado pelo sujeito, que por sua vez, é ele mesmo também recriado pela sua relação no mundo...” (p. 77)

"As representações sociais são uma estratégia desenvolvida por atores sociais para enfrentar a diversidade de um mundo que embora pertença a todos, transcende a cada um individualmente. Nesse sentido, elas são um espaço potencial de fabricação comum, onde cada sujeito vai além de sua própria individualidade para entrar em domínio diferente, ainda que fundamentalmente relacionado: o domínio do espaço público”. (p. 81)

As representações sociais, mediações entre o sujeito e o objeto-mundo, que os profissionais tecem para descrever interpretações quase sempre incompletas sobre a pobreza, o desenvolvimento, a raça, o social, a política, o conhecimento, transcendem sim, a cada indivíduo, de acordo com sua inserção e concepção do mundo. Esta inserção dife- renciada pode estar permeada de preconceito, como também pode ter sido forjada pelos meios de comunicação, com pouca possibilidade de ser decodificada através do conhecimento, face à precariedade do acesso. A mudança requerida é que a compreensão da realidade evolua paralela ao conhecimento, superando as representações sociais limitadas ao senso comum.

Pensamos que deve ser melhor conhecida a direta relação entre analfabetismo, pobreza, raça e controle da natalidade. A prática pôde revelar que a população de usuárias das unidades de saúde tanto real como potencial, é constituída em sua maioria de negros, e para os profissionais são eles quem mais representam a pobreza. É freqüente ouvir nas unidades de saúde: "você acha que deve continuar a, aumentar esta população negra, pobre, analfabeta, que só aumenta a miséria do nosso país?" ou "trabalho sim com o kit da Benfam, o que me move é o senso humanitário, dado por minha profissão e estas questões políticas não me interessam". Pensamos que não é circunstancial a relação entre diminuição da pobreza a raça. As teses eugênicas dos países industrializados influenciaram até a década de 50, e só então foram transformadas para explosão demográfica, apoiada nas teorias malthusianas. Nas representações sociais identificadas está posta a intrínseca relação entre controle da natalidade, raça e pobreza.

\section{CONSIDERAÇÕES FINAIS}

A intenção deste ensaio é apresentar as principais inquietações sobre os significados da contracepção, a formação acadêmica e o PAISM. Aqui foram registrados o pensamento e as indagações próprias ou compartilhadas sobre como está encadeado o pensar e o fazer contraceptivo, ao mesmo tempo que se elencaram alguns entraves que estão presentes no trabalho. Foram relacionados alguns elementos que interferem na compreensão da política contraceptiva como também daqueles originados da desinformação profissional. Estes elementos trazem em seu interior preconceitos e intolerâncias dentro de um trabalho que é de fundamental importância para a população feminina.

Iniciamos a tentativa de analisar o paralelo entre miséria e aumento do contingente popu- 
lacional e de explicar o significado da superpopulação dentro das concepções de desenvolvimento. Percebemos que nos últimos anos o Brasil ficou perto do alcance da taxa populacional prevista como satisfatória pelos agentes internacionais, levando estes a deslocarem seus trabalhos para outros países do Terceiro Mundo, principalmente a África. Não obstante, se constatou o agravamento dos índices reais da pobreza absoluta. É certo que nunca se teve tanto desemprego e fome e poucas dúvidas restam sobre a incompetência do Estado brasileiro em gerar possibilidades de desenvolvimento e de melhorar as condições de vida. A par disso, o controle da natalidade existiu independente e distante do processo de desenvolvimento.

A situação decorrente do modelo neoliberal, com consequiência na restrição do número de empregos, além da diminuição do poder de compra dos salários para os poucos que chegam a possuir emprego, abrigou as medidas controlistas até mesmo diante do insucesso do desenvolvimento. Como não estava prevista a assimilação ao processo produtivo da parte maior da população, só restou permitir a sua gradual redução e assistir a ela. Dessa maneira, continua garantido o espaço das entidades controlistas que mascaram suas ações através da assunção das práticas educativas, com o intuito não de educar, mas de assegurar a redução numérica da população. Dentro da política neoliberal está concebida a existência de bolsões de pobreza e a todo momento ouvimos a fala de profissionais de saúde que alia o potencial de recursos disponíveis e ao medo de que sejam desperdiçados "com esta população pobre que precisa parar de crescer". Presenciamos uma política de controle da natalidade de caráter focalizado, que busca a seletividade e contribui para manter a desigualdade.

Em relação à contracepção e conflitos entre classes, vários atores sociais estão presentes frente ao Estado e dentre eles evidenciam-se em dois planos: as relações econômicas internacionais como o Banco Mundial, o Fundo Monetário Internacional (FMI) e a Organização das Nações Unidas (ONU) com vinculações aos países centrais a hegemônicos. No plano interno as relações são estabelecidas por: Ministério da Saúde, Congresso Nacional, entidades denominadas sem fins lucrativos como a Sociedade Civil de Bem Estar Familiar (Benfam) e o Centro de Pesquisa de Assistência Integrada à Saúde da Mulher (Cepaimc), entidades formadoras de profissionais a serviços públicos e privados de saúde. Com este conjunto por demais heterogêneo, a política contraceptiva comporta antagônicas interpretações, resultando na polarização, descontinuidade e fragmentação, que espelham confrontos entre as posições.

Levantamos também estas considerações: a quem interessaria mais a política de contracepção: ao Estado ou à população? A par de todas as discussões, percebemos entretanto, que a princípio o interesse é mútuo - o Estado neoliberal com o projeto de gerar o desenvolvimento, quer precisar quantitativamente sua população, enquanto que parte da população feminina, tomando-se consciente da necessidade de constituir-se como força de trabalho, precisa evitar a prole numerosa. Porém, vemos que os interesses a desejos entre Estado a população não são complementares. Percorrem trilhas diversas para atender de um lado à dominação econômica e do outro a aspectos individuais e subjetivos. Consideramos também que esta teia ampla confunde o profissional despreparado e em conseqüência serve para mascarar intenções falsas, opostas ao próprio interesse da usuária dos serviços de saúde.

As forças múltiplas que compõem o Estado interagem de forma diversificada e oposta, quando o assunto é contracepção. Estas diferenças sem dúvida se refletem no trabalho desenvolvido pelos profissionais, ocasionando sistemáticos bloqueios na comunicação entre os membros da equipe. Como as informações são diferentes, a usuária continua sendo conduzida ao uso de contraceptivos, de acordo com a vontade individual e própria de cada profissional de saúde.

O Estado comporta estas contradições nas suas formas de organização e interage com as instituições que viabilizam a política de controle da natalidade. O trabalho contraceptivo também contempla duas esferas - pública e privada, sendo que a pública não sobrevive sem a privada, porque esta que, em última instância, ajuda a sustentação da primeira, abastecendo as unidades públicas com uma parcela dos insumos. Mesmo que o Ministério da Saúde possa ser o principal repassador dos insumos, estes 
são em sua maior parte gerados com recursos das entidades privadas internacionais a nacionais, atendendo a acordos firmados.

Outro importante aspecto em relação à política social de controle da natalidade se mostra quando percebemos que, de maneira semelhante às políticas de saúde, as contradições de classe ultrapassam a esfera organizativa do Estado em nível macro e chegam a interferir no cotidiano das unidades de saúde. A manutenção da hierarquia, a reiteração das formas de poder, a opção por inculcar e não por desenvolver a prática pedagógica, a acentuada separação entre trabalho manual e intelectual, a fala incompreensível para a maioria das usuárias, todas juntas refletem a diferenciação de classe entre profissionais. Desta forma comprometem a possibilidade de estabelecer a horizontalidade da relação entre profissionais e usuárias, impedindo a democratização das informações e a possibilidade de uma formação em saúde, que de fato envolva profissionais e usuárias.

A título de exemplo, podemos considerar a questão da laqueadura tubária, fazendo a seguinte indagação: mantemos o mesmo discurso em relação à laqueadura tubária quando tratamos mulheres de diferentes classes sociais? Ou temos um discurso para a classe média e alta que de posse de todas as informações possam optar pela esterilização a um outro discurso que deslegitima o desejo manifesto por parte da usuária das classes populares, quando esta também se manifesta pela esterilização? A questão passa somente pela discussão entre população necessária e desnecessária? Há o desejo espontâneo pela laqueadura, ou este é construído pela mídia e/ou por profissionais de saúde com posturas controlistas? Vemos que questões como estas carecem de serem desveladas para se depurar o que é vontade/desejo legítimo, representação social, ou ainda, manipulação ideológica, e irão certamente compor o estudo mais amplo, do qual este é parte introdutória.

A inquietação em melhor entender estes três aspectos caminha no sentido de valorar o que é dito nas falas das usuárias de saúde e nos discursos profissionais daqueles que estão no momento gerenciando programas contraceptivos, ou vivendo a prática contraceptiva na direta relação com as usuárias. Con- sideramos em que contexto a vontade ou o desejo por um determinado método se expressa a quais as condições encontradas para tal expressão. Indagamos também o grau de preconceito dos profissionais em relação a esta vontade e se ela é ou não conseqüência do emergente, da necessidade social e em qual patamar o desejo ou necessidade se inscreve.

As polarizações existentes que desconsideram o emergente, reafirmando apenas o desejo ou reafirmando meramente posições ideológicas de dominação, deformação e legitimação, podem estar descontextualizadas e distorcidas. Por outro lado seria o emergente justificativa para tudo? Voltando à questão da laqueadura tubária, devemos simplesmente considerar como legítimo o pedido freqüente da usuária pela laqueadura e encaminhá-la aos recursos disponíveis, sejam eles de qualquer origem?

De todas estas considerações, a mais importance diz respeito à necessidade de fazer valer o PAISM, reafirmando seus princípios, objetivos a origem de seus recursos para interpretar a fundo os interesses que estão em jogo e introduzir este conhecimento junto à formação na área da saúde da mulher, somado ao conhecimento da prática pedagógica.

Concluímos esta fase preliminar, reiterando a necessidade de incorporar à prática pedagógica a proposta de capacitação técnica. Segundo Valla \& Stotz (1993: 77), "A proposta de capacitação técnica sugere que as classes trabalhadoras organizadas crescem em autonomia e iniciativa na medida em que possuem os conhecimentos técnicos para poder reivindicar e fiscalizar os serviços básicos necessários à reprodução de sua força de trabalho. É justamente por saber que quem detém os conhecimentos técnicos para esta fiscalização são os profissionais de saúde, que se propõe a aliança profissional/movimento popular. Na realidade não é qualquer profissional que, possui os conhecimentos técnicos necessários para este tipo de aliança, pois embora a formação universitária 'legitime' o profissional, não o prepara necessariamente para esta aliança. Pode-se dizer que a formação universitária o capacita, ou melhor, o legitima a pensar nos conteúdos necessários para esta aliança”. Esta proposta resume a intenção básica deste estudo. 


\section{RESUMO}

\section{STEPHAN-SOUZA, A. I. Relendo a}

Política de Contracepção: O Olhar de um Profissional Sobre o Cotidiano das Unidades Públicas de Saúde. Cad. Saúde Públ., Rio de Janeiro, 11 (3): 408-424, jul/ set, 1995.

Este ensaio é parte de um estudo mais amplo sobre a relação do Estado brasileiro e a política contraceptiva e precede uma investigação nas unidades de saúde do Rio de Janeiro, onde pretende analisar o pensamento de profissionais e usuárias sobre a contracepção. Retrata as considerações de uma assistente social que vivenciou as ações de planejamento familiar em unidades periféricas de saúde e pretende oferecer contribuições que possam facilitar o trabalho nesta área. Para isto discute alguns elementos que interferem na prática, tais como a formação acadêmica, as representações sociais e também tece críticas ao PAISM como política oficial de contracepção.

Palavras-Chave: Contracepção; Política de Contracepção; Planejamento Familiar; Saúde da Mulher

\section{REFERÊNCIAS BIBLIOGRÁFICAS}

ABRANCHES, S. H.; SANTOS, W. G. \& COIMBRA, M. C., 1989. Política Social de Combate à Pobreza. Rio de Janeiro: Jorge Zahar.

CARNEIRO, F. \& WERNECK, J., 1992. Planejamento familiar a atraso. Teoria a Debate, 17: 4650.

CHAUÍ, M., 1994. Convite à Filosofia. São Paulo: Ática.

CONFERÊNCIA DO CAIRO, 1994. Palestra sobre a Conferência do Cairo durante o $9^{\circ}$ Encontro de Assuntos Populacionais, Caxambu: Associação Brasileira de Estudos Populacionais. (Mimeo.)
FONSECA-SOBRINHO, D., 1993. Estado $e$ População: uma História do Planejamento Familiarno Brasil. Rio de Janeiro: Rosa dos Tempos.

O GLOBO, 1992. Príncipe Charles faz apelo à Rio92, O Globo, 22 de abril.

GONÇALVES, R., 1994. Ô Abre-Alas: A Nova Inscrção do Brasil na Economia Mundial. Rio de Janeiro: Relume-Dumará.

JOVCHELOVITCH, S. \& GUARESCHI, P., 1994. Textos em Representações Sociais. Petrópolis: Vozes.

MARQUES, M. B., 1991. Ciência, Tecnologia, Saúde a Desenvolvimento Sustentado. Rio de Janeiro: Fundação Oswaldo Cruz.

MARTINS, G., 1993. População, Meio ambiente e Desenvolvimento. Campinas: Unicamp.

MS (Ministério da Saúde)/SNPES (Secretaria Nacional de Programas Especiais em Saúde/ DINSAMI (Divisão de Saúde Matemo-Infantil), 1989. Assistência Integral à Saúde da Mulher: Módulo 3. Brasília, DF: Ministério da Saúde.

PENA, M. V. J., 1991. Política a população: dados sobre um Estado de duas caras. Revista Phisys, 1: 97-115.

ROCHA, M. I. B., 1993. Política Demográfica e Parlamento. Debates e Decisões sobre o Controle da Natalidade. Tese de Doutorado, Campinas: Núcleo de Estudos da População, Universidade Estadual de Campinas.

SCHRAIBER, L., 1989. Educação Médica $e$ Capitalismo. São Paulo: Hucitec.

SZMRECSÁNYI, M. I., 1988. Educação $e$ Fecundidade. São Paulo: Hucitec.

VAllA, V. V. \& STOTZ, E., 1993. Participação Popular, Educação e Saúde: Teoria e Prática. Rio de Janeiro: Relume-Dumará. 